\title{
Determination of digesta flow entering the omasal canal of dairy cows using different marker systems
}

\author{
Seppo Ahvenjärvi ${ }^{1 \star}$, Aila Vanhatalo ${ }^{1}$, Kevin J. Shingfield ${ }^{1,2}$ and Pekka Huhtanen ${ }^{1}$ \\ ${ }^{1}$ MTT Agrifood Research Finland, FIN-31600 Jokioinen, Finland \\ ${ }^{2}$ School of Food Biosciences, The University of Reading, PO Box 226, Reading RG6 6AP, UK
}

(Received 7 June 2002 - Revised 17 January 2003 - Accepted 10 February 2003)

\begin{abstract}
Four studies were conducted to compare the effect of four indigestible markers (LiCoEDTA, Yb-acetate, Cr-mordanted straw and indigestible neutral-detergent fibre (INDF)) and three marker systems on the flow of digesta entering the omasal canal of lactating dairy cows. Samples of digesta aspirated from the omasal canal were pooled and separated using filtration and high-speed centrifugation into three fractions defined as the liquid phase, small particulate and large particulate matter. Co was primarily associated with the liquid phase, $\mathrm{Yb}$ was concentrated in small particulate matter, whilst $\mathrm{Cr}$ and INDF were associated with large particles. Digesta flow was calculated based on single markers or using the reconstitution system based on combinations of two $(\mathrm{Co}+\mathrm{Yb}, \mathrm{Co}+\mathrm{Cr}$ and $\mathrm{Co}+\mathrm{INDF})$ or three markers $(\mathrm{Co}+\mathrm{Yb}+\mathrm{Cr}$ and $\mathrm{Co}+\mathrm{Yb}+\mathrm{INDF})$. Use of single markers resulted in large differences between estimates of organic matter (OM) flow entering the omasal canal suggesting that samples were not representative of true digesta. Digesta appeared to consist of at least three phases that tended to separate during sampling. OM was concentrated in particulate matter, whilst the liquid phase consisted mainly of volatile fatty acids and inorganic matter. Yb was intimately associated with nitrogenous compounds, whereas $\mathrm{Cr}$ and INDF were concentrated in fibrous material. Current data indicated that marker systems based on $\mathrm{Yb}$ in combination with $\mathrm{Cr}$ or INDF are required for the accurate determination of OM, $\mathrm{N}$ and neutral-detergent fibre flow. In cases where the flow of water-soluble nutrients entering the omasal canal is also required, the marker system should also include Co.
\end{abstract}

Dairy cows: Digestibility: Markers: Rumen: Omasum

In an attempt to improve the efficiency of nutrient utilisation in ruminant animals a number of metabolisable energy (for example, Agricultural and Food Research Council (AFRC), 1990) and protein systems (for example, AFRC, 1992; National Research Council, 2001) have been developed. In all cases these systems are based on data derived from fundamental studies that have measured the fate of ingested nutrients in the rumen and the supply of nutrients to the host animal. Errors associated with the prediction of nutrient supply using these models are to a large extent a reflection of the inherent reliability of measurements of duodenal nutrient flow from which they are based. Improving the accuracy of flow measurements is central to reducing errors in the prediction of nutrient supply.

Measurements of digesta flow have traditionally relied on the collection of spot digesta samples via simple-T duodenal cannulas and estimating digesta flow using indigestible markers. An alternative system that estimates the flow of nutrients entering the omasal canal has been developed (Huhtanen et al. 1997). Compared with sampling from the abomasum or duodenum this technique offers several potential benefits. Surgical intervention is reduced, measurements obtained are less affected by endogenous secretions and digestion of microbial cells can be avoided. However, one major shortcoming of this approach arises from the collection of samples that are not representative of true digesta entering the omasal canal (Huhtanen et al. 1997; Ahvenjärvi et al. 2000).

Faichney (1975) suggested that digesta could be considered as two phases such that unrepresentative sampling occurs due to a tendency for digesta to separate during collection. As a result, the relative proportion of each phase in collected samples can become biased compared with true digesta. Provided that the assumption of two homogeneous phases holds true, unrepresentative samples can be reconstituted to represent true digesta using markers that exhibit differential affinities for individual digesta phases (Faichney, 1975). However, more recent studies have indicated that the assumption of a single homogeneous particulate phase is too simplistic (Siddons et al. 1985; Satter et al. 1987; Huhtanen et al. 1994), whilst the use of the double-marker system has been extended to accommodate three or more phases (France \& Siddons, 1986). Based on theoretical considerations, unrepresentative samples can be reconstituted to true digesta provided that markers associate with individual phases of digesta that have unique 
flow characteristics. The present study was conducted to evaluate the effect of different markers and marker systems on the accuracy of measurements of the flow of digesta entering the omasal canal.

\section{Materials and methods}

\section{Animals and diets}

Measurements of digesta flow entering the omasal canal of lactating dairy cows were determined in four $4 \times 4$ Latin square experiments. Experimental diets were typical of diets fed in practice. In each experiment, cows were fed twice daily at $12 \mathrm{~h}$ intervals. In experiment I, four cows received grass silage $(600 \mathrm{~g} / \mathrm{kg} \mathrm{DM})$ supplemented with barley, barley and urea, barley and solvent-extracted rapeseed meal and barley and heat-moisture-treated rapeseed cake (Ahvenjärvi et al. 1999). For experiment II (Ahvenjärvi et al. 2002a), grass silage was progressively replaced with whole crop barley silage $(0,200,400$, and $600 \mathrm{~g} / \mathrm{kg}$ silage $\mathrm{DM})$ and offered to four cows receiving $8.8 \mathrm{~kg} \mathrm{DM}$ of a cereal-based concentrate/d. In experiment III (Ahvenjärvi et al. 2002b), four cows received a basal diet consisting of grass-red clover silage, supplemented according to a $2 \times 2$ factorial arrangement of treatments with barley $(0 v .5 \cdot 1 \mathrm{~kg}$ $\mathrm{DM} / \mathrm{d})$ and rapeseed meal ( 0 v. $1.9 \mathrm{~kg} \mathrm{DM} / \mathrm{d})$. In experiment IV (KJ Shingfield, S Ahvenjärvi, V Toivonen, KVV Nurmela, P Huhtanen and JM Griinari, unpublished results), four cows received a basal diet of grass silage $(600 \mathrm{~g} / \mathrm{kg} \mathrm{DM})$ and a cereal-based concentrate fed alone or supplemented with $500 \mathrm{~g}$ rapeseed, soyabean or linseed oil/d. During digesta collection in experiments I, III and IV, silage intake was restricted to proportionately 0.95 of that fed before the fitting of the omasal sampling device, whilst cows were offered silage ad libitum in experiment II.

\section{Flow markers}

Digesta flow was determined using four indigestible markers, LiCoEDTA, Yb-acetate, Cr-mordanted straw and indigestible neutral-detergent fibre (INDF). Coarsely chopped barley straw was soaked in tap water overnight, then washed using neutral detergent rinsed and subsequently labelled with $\mathrm{Cr}$ according to Udén et al. (1980). Cr-mordanted straw $(2.9 \mathrm{~g} \mathrm{Cr} / \mathrm{d})$ was enclosed within a paper towel and administered twice daily on top of the rumen mat via the cannula at 12-hourly intervals. LiCoEDTA, prepared according to Udén et al. (1980) and either $\mathrm{Yb}$-acetate (experiments I, III, and IV) or Ybchloride (experiment II) were dissolved in distilled water and infused into the rumen at a constant rate using a peristaltic pump ( $1.6 \mathrm{~g}$ Co and $1.5 \mathrm{~g} \mathrm{Yb/d} \mathrm{respectively).} \mathrm{The}$ daily rate of marker administration was based on appearance in faeces determined as the product of faecal marker concentration and faecal output. Total faecal collections were performed over 3 (experiment II) or 4 (experiments I and IV) d. For experiment III, faecal excretion was determined using acid-insoluble ash and INDF as internal markers. In experiment $\mathrm{I}$, administration of $\mathrm{Cr}$ commenced $120 \mathrm{~h}$ and that of $\mathrm{Yb}$ and $\mathrm{Co} 96 \mathrm{~h}$ before digesta collection. In experiments II, III and IV, in order to facilitate equilibration of marker concentrations in digesta and faeces, priming doses were administered. Priming doses of $\mathrm{Cr}$ represented 1.25 times the daily rate of administration, whereas that of $\mathrm{Co}$ and $\mathrm{Yb}$ was equivalent to 1.5 times the daily infusion rate. Administration of $\mathrm{Cr}$ commenced $72 \mathrm{~h}$ (experiment II) or $84 \mathrm{~h}$ (experiments III and IV) before collection of digesta from the omasal canal, whereas $\mathrm{Co}$ and $\mathrm{Yb}$ were administered $48 \mathrm{~h}$ (experiment II) or $60 \mathrm{~h}$ (experiments III and IV) before sample collection. For experiments II and IV total faecal collection started $12 \mathrm{~h}$ after digesta collection.

\section{Sampling procedures}

Cows were fitted with $100 \mathrm{~mm}$ internal diameter rumen cannulas (Bar Diamond, Inc., Parma, ID) while spot samples of digesta entering the omasal canal were collected according to Huhtanen et al. (1997) incorporating the modifications of Ahvenjärvi et al. (2000, 2001). Samples of $400-500 \mathrm{ml}$ were collected using a sampling device installed in the omasal canal and a pump that applied alternating negative and positive pressures across the sampling device. Digesta was collected across three (experiment II) or four consecutive sampling days (experiments I, III and IV) during a $12 \mathrm{~h}$ period following morning feeding. Sampling protocols allowed twelve samples that represented each hour after morning feeding to be collected, with the exception of experiment III, in which eight samples were obtained, equivalent to $1.5 \mathrm{~h}$ sampling intervals. Immediately after collection digesta samples were frozen and stored at $-20^{\circ} \mathrm{C}$. At the end of each period, samples were pooled to provide a composite sample of digesta. In order to facilitate determinations of the chemical composition for each digesta phase, composite samples were separated into large-particle, small-particle, and liquid components. Composite digesta was squeezed through one layer of cheesecloth and the solids retained on the cheesecloth were defined as large particles. The supernatant fraction obtained by centrifugation at $10000 \mathrm{~g}$ for $30 \mathrm{~min}$ was defined as the liquid phase, while the pellet was defined as small particulate matter. In experiment III, this procedure included washing large particulate matter with saline to remove small particles and loosely attached microbes.

Use of the double-marker system is dependent on separating digesta into liquid and particulate phases. These phases are subsequently referred to as solid and fluid phases in the context of double-marker systems in order to make the distinction from triple-marker systems where digesta is separated into three phases (large-particle, small-particle and liquid phase).

\section{Chemical analysis}

Large-particle, small-particle and liquid phases of omasal canal digesta were lyophilized to a constant weight before chemical analysis. Silage and faeces were dried to a constant weight in a forced air oven at $60^{\circ} \mathrm{C}$. Dried samples were milled through a $1 \mathrm{~mm}$ screen before chemical analysis. The DM concentration of air-equilibrated samples was determined based on weight loss over $18 \mathrm{~h}$ 
in a forced air oven at $105^{\circ} \mathrm{C}$. Silage DM concentration was corrected for volatile losses according to Huida et al. (1986). Feed ingredients and components of omasal canal digesta were determined for ash after ignition in a muffle furnace at $600^{\circ} \mathrm{C}$ for $18 \mathrm{~h}$. $\mathrm{N}$ content of fresh silage was measured by the Kjeldahl procedure using $\mathrm{CuSO}_{4}$ as a catalyst, whilst that of lyophilized digesta was determined using a Dumas-type N analyser (Leco FP-428; Leco Corporation, St Joseph, MI). Concentration of neutraldetergent fibre (NDF) was determined according to Van Soest et al. (1991). Concentrations of INDF in silage, concentrates, faeces, large particles and small particles were determined in duplicate following incubation of $2-4 \mathrm{~g}$ samples in polyester bags of $6 \mu \mathrm{m}$ pore size for $288 \mathrm{~h}$ in the rumen of two cows. Once removed from the rumen, samples were rinsed in a household washing machine, extracted for $60 \mathrm{~min}$ in NDF solution at $100^{\circ} \mathrm{C}$, rinsed and dried to constant weight at $60^{\circ} \mathrm{C}$. Omasal digesta and faeces were analysed for $\mathrm{Co}, \mathrm{Yb}$ and $\mathrm{Cr}$ according to Williams et al. (1962). Since volatile fatty acids are endproducts of organic matter (OM) digestion in the rumen, the OM content of the liquid phase was calculated as DM-(ash + volatile fatty acids). Volatile fatty acids accounted for 773 (SD 37.9), 775 (SD 54.7), 755 (SD 103.3 ) and 822 (SD 58.0) g/kg OM in the liquid phase of digesta for experiments I, II, III and IV, respectively.

\section{Calculations}

Digesta flow was calculated based on single markers ( $\mathrm{Co}, \mathrm{Yb}, \mathrm{Cr}$ and INDF) and the reconstitution technique pioneered by Faichney (1975) using a combination of two or three markers. Use of the double- and triplemarker systems is well established and they have been extensively documented in the literature (Faichney, 1975; France \& Siddons, 1986). Measurements of digesta flow using double-marker systems were based on Co as the fluid-phase marker and $\mathrm{Yb}, \mathrm{Cr}$ and INDF as independent solid-phase markers (systems $\mathrm{Co}+\mathrm{Yb}, \mathrm{Co}+\mathrm{Cr}$, and $\mathrm{Co}+$ INDF respectively). Flows estimated according to triple-marker systems were based on $\mathrm{Co}$ as the liquid-, $\mathrm{Yb}$ as the small-particle- and either $\mathrm{Cr}$ or INDF as largeparticle-phase markers (systems $\mathrm{Co}+\mathrm{Yb}+\mathrm{Cr}$, and $\mathrm{Co}+\mathrm{Yb}+\mathrm{INDF}$ respectively). Because digesta was fractionated into three phases, small particulate matter within the double-marker system could be considered as both a component of the liquid phase or large particulate matter. The effect of sample fractionation on the distribution of markers between solid and fluid phases and estimates of digesta-flow measurements was also assessed. Total tract digestibility was based on total faecal collection in all cases, with the exception of experiment III where faecal output was determined based on acid-insoluble ash and INDF as an internal marker.

\section{Sensitivity}

In order to assess the sensitivity of digesta-flow measurements to erroneous estimates of marker administration, the daily dose of each marker was sequentially multiplied by 1.1 (equivalent to a $10 \%$ overestimate of daily marker administration) and relative changes in $\mathrm{OM}, \mathrm{N}$ and NDF flow were calculated based on $\mathrm{Co}+\mathrm{Yb}+\mathrm{Cr}$ and $\mathrm{Co}+$ $\mathrm{Yb}+$ INDF triple-marker systems.

\section{Statistical analysis}

Data concerning estimates of digesta flow and nutrient digestibility in the rumen based on different marker systems for each experiment were subjected to ANOVA for repeated measurements using the Mixed procedure of SAS (Littell et al. 1996) according to the following statistical model:

$$
\begin{aligned}
Y_{i j k}= & \mu+A_{i}+P_{j}+D_{k}+(A P)_{i j}+M_{l}+(A M)_{i l}+(P M)_{j l} \\
& +(D M)_{k l}+e_{i j k l}
\end{aligned}
$$

where $\mathrm{A}$ is the random effect of animal, $\mathrm{P}, \mathrm{D}$ and $\mathrm{M}$ are the fixed effects of period, diet and marker system respectively. Interactions between these effects were considered random when one of the terms was a random effect. The covariance structure of residuals for individual animals within experimental period was constructed by stipulating an unstructured covariance structure within the REPEATED statement of SAS and (AP) $)_{\mathrm{ij}}$ as the effect of subject.

The precision of flow measurements was assessed on the basis of associated $\mathrm{CV}$ for each marker system, calculated as the square root of estimated variance for the effect of $(\mathrm{AP})_{\mathrm{ij}}$ (equivalent to the diagonal element of the covariance structure) divided by the estimated mean. Estimation of parameters was considered satisfactory when convergence criteria fell below a threshold of $10^{-5}$. Owing to the large number of covariance parameter estimates (five variance and ten covariance estimates) relative to the number of animals (four cows), convergence criteria in many cases were not satisfied when flow estimates derived using all marker systems were analysed simultaneously. As a result, the statistical model was fitted independently for double- and triple-marker systems. In cases where this approach failed to satisfy convergence criteria, the following model was fitted to each marker system in order to evaluate residual variation:

$$
Y_{i j k}=\mu+A_{i}+P_{j}+D_{k}+e_{i j k} .
$$

For data analysed using this model, standard deviation was calculated as the square root of the error term $\left(e_{i j k}\right)$. Marker systems analysed using a common statistical model are denoted by common prefixes in results tables. Pair-wise differences between marker systems were determined using $t$ tests. Underlying assumptions of the applied statistical model were evaluated by examining residuals for constancy of error variance. Correlation coefficients between marker systems within each study were assessed using the CORR procedure within SAS (SAS Institute Inc., Cary, NC). In all cases the mean value across all treatments and experiments is reported. The relationship between reconstitution factors (RF) estimated for the solid phase using the $\mathrm{Co}+\mathrm{Yb}$ double-marker system in combination with the separation of digesta by centrifugation or filtration was assessed according to the principles outlined by St-Pierre (2001) using a model that assumes 
experiment has a random effect on the overall intercept and slope of the fitted regression.

\section{Results}

DM intake and milk production reflected the wide range of diets offered and variation in the stage of lactation of animals used in the present studies (Table 1).

One observation in experiment II was identified as an outlier based on the plots of residuals for constancy of error variance and was removed. In total, sixty-two individual cow measurements were used to evaluate the effects of marker type and marker system on estimates of the flow of digesta entering the omasal canal.

\section{Chemical composition of digesta phases}

Measurements of chemical composition indicated substantial differences between digesta phases (Table 2). Concentrations of $\mathrm{OM}$ were highest for large particulate matter and lowest in the liquid phase, whereas $\mathrm{N}$ was concentrated in small particulate matter but was relatively low in the liquid phase. Large particles contained greater amounts of NDF compared with small particles. The liquid phase was not submitted to NDF analysis since particulate matter was essentially removed by centrifugation at $10000 \mathrm{~g}$ for $30 \mathrm{~min}$ and therefore the liquid phase was assumed to be devoid of fibre. Relative concentrations of individual markers in digesta entering the omasal canal are presented in Table 3. Concentrations of Co were relatively high in the liquid phase but substantially lower in large and small particles. $\mathrm{Yb}$ was primarily associated with particulate matter, with concentrations being greater in small particles, whilst $\mathrm{Cr}$ and INDF were concentrated in large particulate matter.

\section{Precision of marker analysis}

Repeated determinations of marker concentrations in each digesta phase indicated that measurements of Co were inherently more precise than that of $\mathrm{Yb}$ or $\mathrm{Cr}$ (Table 4). Furthermore, associated standard deviations indicated that the determination of $\mathrm{Yb}$ was in general less precise than that of $\mathrm{Cr}$ or INDF.

\section{Separation of fluid and solid phases}

Separation of digesta by centrifugation resulted in higher $\mathrm{Yb}$ concentrations in the solid than fluid phase (Table 5). In contrast, when phases were separated by filtration through one layer of cheesecloth, $\mathrm{Yb}$ accumulated in the fluid phase. Separation attained through filtration resulted in smaller differences between the two phases, and in some cases concentrations were similar in solid and fluid

Table 1. Dry-matter intake and milk yield*

(Mean values and standard deviations)

\begin{tabular}{|c|c|c|c|c|c|c|c|c|}
\hline \multirow[b]{2}{*}{ Expt... } & \multicolumn{2}{|c|}{ I } & \multicolumn{2}{|c|}{ II } & \multicolumn{2}{|c|}{ III } & \multicolumn{2}{|c|}{ IV } \\
\hline & Mean & sD $\dagger$ & Mean & SD & Mean & SD & Mean & SD \\
\hline DM intake $(\mathrm{kg} / \mathrm{d})$ & $14 \cdot 7$ & $3 \cdot 2$ & $21 \cdot 4$ & $2 \cdot 4$ & $16 \cdot 4$ & $2 \cdot 3$ & $18 \cdot 2$ & 0.9 \\
\hline Milk yield $(\mathrm{kg} / \mathrm{d})$ & 23.2 & 4.5 & 33.8 & 3.9 & $22 \cdot 4$ & 3.8 & $20 \cdot 8$ & 4.2 \\
\hline
\end{tabular}

${ }^{*}$ For details of procedures, see pp. 42-43.

$\dagger$ Standard deviation within individual experiments.

Table 2. Distribution of chemical components in digesta* (Mean values and standard deviations)

\begin{tabular}{|c|c|c|c|c|c|c|c|c|}
\hline \multirow{2}{*}{$\begin{array}{l}\text { Expt... } \\
\text { Phase }\end{array}$} & \multicolumn{2}{|c|}{1} & \multicolumn{2}{|c|}{ II } & \multicolumn{2}{|c|}{ III } & \multicolumn{2}{|c|}{ IV } \\
\hline & Mean & sD† & Mean & SD & Mean & SD & Mean & SD \\
\hline \multicolumn{9}{|l|}{ OM (g/kg DM) } \\
\hline Large-particle & 912 & $11 \cdot 8$ & 905 & $8 \cdot 3$ & 903 & $9 \cdot 3$ & 905 & $13 \cdot 7$ \\
\hline Small-particle & 833 & 9.4 & 846 & $12 \cdot 0$ & 829 & $17 \cdot 9$ & 856 & $16 \cdot 4$ \\
\hline Liquidł & 111 & $20 \cdot 8$ & 113 & 29.9 & 102 & $72 \cdot 9$ & 85 & $30 \cdot 9$ \\
\hline \multicolumn{9}{|l|}{ N (g/kg DM) } \\
\hline Large-particle & 29.5 & $2 \cdot 6$ & $31 \cdot 0$ & $3 \cdot 8$ & $30 \cdot 2$ & $4 \cdot 1$ & $33 \cdot 1$ & $2 \cdot 2$ \\
\hline Small-particle & 59.4 & $2 \cdot 0$ & 63.4 & $4 \cdot 3$ & $65 \cdot 7$ & 1.8 & 63.4 & $2 \cdot 4$ \\
\hline Liquid & $17 \cdot 3$ & $2 \cdot 2$ & $20 \cdot 9$ & $2 \cdot 7$ & $11 \cdot 3$ & $2 \cdot 2$ & $23 \cdot 0$ & $3 \cdot 0$ \\
\hline \multicolumn{9}{|l|}{ NDF (g/kg DM) } \\
\hline Large-particle & 573 & 32.9 & 614 & $46 \cdot 9$ & 612 & $32 \cdot 2$ & 529 & 29.8 \\
\hline Small-particle & 25 & $4 \cdot 2$ & 23 & $24 \cdot 6$ & 77 & $12 \cdot 4$ & 53 & $11 \cdot 8$ \\
\hline Liquid & ND & ND & ND & ND & ND & ND & ND & ND \\
\hline
\end{tabular}

OM, organic matter; NDF, neutral-detergent fibre; ND, not determined.

${ }^{*}$ For details of procedures, see pp. 42-43.

† Standard deviation within individual experiments.

$\ddagger$ Volatile fatty acids were deducted from total organic matter content of the liquid phase. 
Table 3. Distribution of relative marker concentrations ${ }^{*}$ in digesta dry matter† (Mean values and standard deviations)

\begin{tabular}{|c|c|c|c|c|c|c|c|c|}
\hline \multirow{2}{*}{$\begin{array}{l}\text { Expt... } \\
\text { Phase }\end{array}$} & \multicolumn{2}{|c|}{ I } & \multicolumn{2}{|c|}{ II } & \multicolumn{2}{|c|}{ III } & \multicolumn{2}{|c|}{ IV } \\
\hline & Mean & SD & Mean & SD & Mean & SD & Mean & SD \\
\hline \multicolumn{9}{|l|}{ Co $\S$} \\
\hline Large-particle & 12 & $2 \cdot 3$ & 14 & $3 \cdot 2$ & 8 & 1.0 & 13 & 1.0 \\
\hline Small-particle & 33 & 4.4 & 35 & $6 \cdot 2$ & 22 & $4 \cdot 3$ & 28 & 3.0 \\
\hline Liquid & 100 & ND\| & 100 & ND & 100 & ND & 100 & ND \\
\hline \multicolumn{9}{|l|}{$\mathrm{Yb} \S$} \\
\hline Large-particle & 40 & $4 \cdot 3$ & 47 & 9.9 & 39 & $7 \cdot 6$ & 51 & $11 \cdot 3$ \\
\hline Small-particle & 100 & ND & 100 & ND & 100 & ND & 100 & ND \\
\hline Liquid & 17 & 4.9 & 18 & $4 \cdot 6$ & 18 & $6 \cdot 7$ & 32 & $10 \cdot 1$ \\
\hline \multicolumn{9}{|l|}{$\mathrm{Cr} 9$} \\
\hline Large-particle & 100 & ND & 100 & ND & 100 & ND & 100 & ND \\
\hline Small-particle & 23 & $2 \cdot 3$ & 22 & $6 \cdot 1$ & 14 & 1.9 & 21 & $3 \cdot 6$ \\
\hline Liquid & 2 & 0.6 & 2 & 0.5 & 1 & 0.4 & 2 & 0.7 \\
\hline \multicolumn{9}{|l|}{ INDF } \\
\hline Large-particle & 100 & ND & 100 & ND & 100 & ND & 100 & ND \\
\hline Small-particle & 4 & 0.8 & 0 & 0 & 3 & 3.9 & 8 & 1.9 \\
\hline Liquid & ND & - & ND & - & ND & - & ND & - \\
\hline
\end{tabular}

INDF, indigestible neutral detergent fibre, ND, not determined.

${ }^{*}$ Relative marker concentrations in digesta DM were calculated by dividing the concentration of individual markers in each phase by the highest measured concentration across all phases and multiplying by 100 . †For details of procedures, see pp. 42-43.

¥ Standard deviation within individual experiments.

$\S$ CoEDTA and Yb-acetate or Yb-chloride was continuously infused into the rumen.

\| Not determined because relative concentrations were assumed to be 100 .

I Barley straw was mordanted with Cr according to Udén et al. (1980).

Table 4. Precision of marker analysis*

(Standard deviations and coefficient of variations between replicate measurements)

\begin{tabular}{|c|c|c|c|c|c|c|c|c|c|c|}
\hline \multirow[b]{3}{*}{ Marker } & \multicolumn{10}{|c|}{ Experiment } \\
\hline & \multicolumn{2}{|c|}{ Mean } & \multicolumn{2}{|c|}{ I } & \multicolumn{2}{|c|}{ II } & \multicolumn{2}{|c|}{ III } & \multicolumn{2}{|c|}{ IV } \\
\hline & sD† & $C V \ddagger$ & SD & $\mathrm{CV}$ & SD & $\mathrm{CV}$ & SD & $\mathrm{CV}$ & SD & $\mathrm{CV}$ \\
\hline Co $(\mathrm{mg} / \mathrm{kg})$ & 4.7 & 0.024 & $6 \cdot 2$ & 0.026 & $2 \cdot 3$ & 0.014 & 4.4 & 0.023 & $6 \cdot 1$ & 0.033 \\
\hline $\mathrm{Yb}(\mathrm{mg} / \mathrm{kg})$ & $10 \cdot 4$ & 0.055 & 6.5 & 0.040 & $6 \cdot 2$ & 0.038 & 14.8 & 0.076 & 13.9 & 0.067 \\
\hline $\mathrm{Cr}(\mathrm{mg} / \mathrm{kg})$ & 10.9 & 0.035 & 11.4 & 0.032 & 10.4 & 0.045 & $12 \cdot 3$ & 0.032 & 9.7 & 0.031 \\
\hline INDF (g/kg) & 8.5 & 0.045 & 11.6 & 0.056 & 11.0 & 0.054 & 6.2 & 0.037 & $5 \cdot 1$ & 0.035 \\
\hline
\end{tabular}

INDF, indigestible neutral-detergent fibre

* For details of procedures, see pp. 42-43.

† Standard deviation between replicates.

$\ddagger$ Coefficient of variation between replicate measurements.

Table 5. Relative concentrations of cobalt and ytterbium in liquid and particulate phases separated by centrifugation or filtration*

(Mean values and standard deviations)

\begin{tabular}{|c|c|c|c|c|c|}
\hline \multirow{2}{*}{$\begin{array}{l}\text { Marker... } \\
\text { Separation method } \dagger\end{array}$} & \multirow[b]{2}{*}{ Phase } & \multicolumn{2}{|c|}{ Co } & \multicolumn{2}{|c|}{$\mathrm{Yb}$} \\
\hline & & Meanł & SD§ & Mean & SD \\
\hline Centrifugation & $\begin{array}{l}\text { Fluid } \\
\text { Solid }\end{array}$ & $\begin{array}{l}100 \\
18-21\end{array}$ & $\begin{array}{c}\text { ND } \\
2 \cdot 6-3 \cdot 8\end{array}$ & $\begin{array}{l}21-42 \\
100\end{array}$ & $\begin{array}{c}8 \cdot 0-13 \cdot 9 \\
\text { ND }\end{array}$ \\
\hline Filtration & $\begin{array}{l}\text { Fluid } \\
\text { Solid }\end{array}$ & $\begin{array}{l}100 \\
12-18\end{array}$ & $\begin{array}{c}N D \| \\
1 \cdot 2-3 \cdot 3\end{array}$ & $\begin{array}{l}100 \\
74-106\end{array}$ & $\begin{array}{c}\text { ND } \\
14 \cdot 6-37 \cdot 0\end{array}$ \\
\hline
\end{tabular}

ND, not determined.

${ }^{*}$ For details of procedures, see pp. $42-43$

†Fluid and solid phases were separated either by centrifugation for $30 \mathrm{~min}$ at $10000 \mathrm{~g}$ or by filtration through cheese cloth.

$\ddagger$ Arithmetic mean within individual experiments.

§Standard deviation within individual experiments.

\| Not determined because relative concentrations were assumed to be 100 . 
phases. Separation method had only minor effects on Co distribution (Table 5). RF estimated for the solid phase according to the $\mathrm{Co}+\mathrm{Yb}$ double-marker system were consistently lower when digesta was separated by centrifugation compared with filtration $\left(\mathrm{RF}_{\mathrm{Filtration}}=1.37 \quad(\mathrm{SE}\right.$ $0 \cdot 16) \mathrm{RF}_{\text {Centrifugation }}+0.053$ (SE 0.070); $r^{2} 0.95, n 63$, $P<0 \cdot 01)$. With the exception of experiment III, separation of digesta by centrifugation resulted in lower flows of OM and NDF entering the omasal canal, but had only relatively minor effects on $\mathrm{N}$ flow (Table 6).

\section{Digesta flow}

Organic matter. Use of single-marker systems resulted in large marker-dependent differences in OM flow entering the omasal canal (Table 7). For most studies, OM flow was lowest based on $\mathrm{Co}$, whereas estimates based on $\mathrm{Yb}$ were higher compared with $\mathrm{Co}$, but lower than those based on $\mathrm{Cr}$ and INDF. In all cases, flows of OM estimated according to single-marker systems were associated with relatively large $\mathrm{CV}$.
Estimates of $\mathrm{OM}$ flow based on $\mathrm{Co}+\mathrm{Cr}$ and $\mathrm{Co}+$ INDF double-marker systems were in good agreement, whereas that using $\mathrm{Co}+\mathrm{Yb}$ was lower for experiments I and III and higher for experiment IV (Table 7). Estimates of OM flow were similar between triple-marker systems, with the exception of experiment III where differences, albeit small, were significant. Examination of CV associated with estimates of OM flow did not indicate a consistent difference between marker systems.

Among single-marker systems, estimates of OM flow using Co were poorly related to estimates based on $\mathrm{Cr}$ and INDF, and only moderately correlated with those derived using $\mathrm{Yb}$ (Table 8). Correlation coefficients between OM flows based on $\mathrm{Yb}$ compared with other single markers were of a similar order of magnitude, while the strongest association existed between estimates based on $\mathrm{Cr}$ and INDF. Comparison of estimates based on single and triple markers indicated that the closest relationship existed between estimates based on $\mathrm{Yb}$ and triple-marker systems.

Nitrogen. In all cases, estimates of $\mathrm{N}$ flow entering the omasal canal were highly consistent between triple-marker

Table 6. Effect of digesta separation method on estimates of organic matter (OM), nitrogen and neutral-detergent fibre (NDF) flow entering the omasal canal based on the cobalt + ytterbium double marker system* (Mean values and coefficients of variation)

\begin{tabular}{|c|c|c|c|c|c|c|c|c|}
\hline \multirow{2}{*}{$\begin{array}{l}\text { Expt... } \\
\text { Separation method } \dagger\end{array}$} & \multicolumn{2}{|c|}{ I } & \multicolumn{2}{|c|}{ II } & \multicolumn{2}{|c|}{ III } & \multicolumn{2}{|c|}{ IV } \\
\hline & Mean & $\mathrm{CV}$ & Mean & CV & Mean & CV & Mean & CV \\
\hline \multicolumn{9}{|l|}{ OM flow (kg/d) } \\
\hline Centrifugation & $5 \cdot 91^{b}$ & 0.09 & $9 \cdot 45^{\mathrm{b}}$ & 0.03 & $4.93^{a}$ & 0.14 & $7 \cdot 72^{b}$ & 0.14 \\
\hline Filtration & $7 \cdot 26^{a}$ & 0.17 & $10 \cdot 58^{a}$ & 0.08 & $4 \cdot 59^{a}$ & 0.31 & $9 \cdot 69^{\mathrm{a}}$ & 0.20 \\
\hline \multicolumn{9}{|l|}{$N$ flow (g/d) } \\
\hline Centrifugation & $313^{b}$ & 0.05 & $480^{\mathrm{a}}$ & 0.04 & $341^{\mathrm{a}}$ & 0.10 & $489^{a}$ & 0.12 \\
\hline Filtration & $324^{\mathrm{a}}$ & 0.08 & $484^{a}$ & 0.04 & $336^{a}$ & 0.12 & $490^{a}$ & 0.11 \\
\hline \multicolumn{9}{|l|}{ NDF flow $(\mathrm{kg} / \mathrm{d})$} \\
\hline Centrifugation & $2 \cdot 18^{b}$ & 0.12 & $4 \cdot 58^{b}$ & 0.05 & $1 \cdot 24^{a}$ & 0.19 & $2 \cdot 30^{b}$ & 0.19 \\
\hline Filtration & $3.52^{\mathrm{a}}$ & 0.27 & $5 \cdot 89^{a}$ & 0.14 & $0.93^{a}$ & $1 \cdot 24$ & $4 \cdot 47^{a}$ & 0.30 \\
\hline
\end{tabular}

Table 7. Effect of marker system on estimates of organic-matter flow $(\mathrm{kg} / \mathrm{d})$ entering the omasal canal ${ }^{*}$ (Mean values and coefficients of variation)

\begin{tabular}{|c|c|c|c|c|c|c|c|c|}
\hline \multirow{2}{*}{$\begin{array}{l}\text { Expt... } \\
\text { Marker }\end{array}$} & \multicolumn{2}{|c|}{ I } & \multicolumn{2}{|c|}{ II } & \multicolumn{2}{|c|}{ III } & \multicolumn{2}{|c|}{ IV } \\
\hline & Mean & CV & Mean & CV & Mean & CV & Mean & CV \\
\hline \multicolumn{9}{|c|}{ Single-marker systems } \\
\hline Co & A $4.46^{d}$ & 0.165 & $A 7 \cdot 36^{c}$ & 0.145 & A $5.05^{c}$ & $0 \cdot 154$ & A $4.95^{\mathrm{C}}$ & 0.182 \\
\hline $\mathrm{Yb}$ & A $5.75^{\mathrm{C}}$ & 0.083 & A $9.23^{b}$ & 0.025 & A $4.94^{C}$ & 0.148 & A $7.04^{b}$ & 0.144 \\
\hline $\mathrm{Cr}$ & A $8 \cdot 24^{b}$ & 0.230 & A $9.76^{a}$ & 0.087 & A $8 \cdot 23^{b}$ & 0.124 & A $9.24^{a}$ & 0.132 \\
\hline INDF & $\mathrm{A} 9 \cdot 12^{\mathrm{a}}$ & 0.239 & A $10 \cdot 01^{a b}$ & 0.149 & A $10.79^{a}$ & $0 \cdot 191$ & A $9.61^{a}$ & 0.156 \\
\hline \multicolumn{9}{|c|}{ Double- and triple-marker systems } \\
\hline $\mathrm{Co}+\mathrm{Yb}$ & B $5.88^{b}$ & 0.069 & B $9.45^{a}$ & 0.022 & B $4.93^{d}$ & $0 \cdot 134$ & $\mathrm{~B} 7.72^{\mathrm{b}}$ & 0.139 \\
\hline $\mathrm{Co}+\mathrm{Cr}$ & B $6.71^{a}$ & 0.140 & B $9.01^{a b}$ & 0.051 & B $6 \cdot 21^{\mathrm{b}}$ & $0 \cdot 120$ & $\mathrm{~B} 7 \cdot 13^{\mathrm{C}}$ & 0.050 \\
\hline $\mathrm{Co}+\mathrm{INDF}$ & $\mathrm{B} 6.76^{\mathrm{a}}$ & 0.095 & B $8.96^{b}$ & 0.064 & $\mathrm{~B} 6 \cdot 66^{\mathrm{a}}$ & 0.140 & B $6.97^{\mathrm{C}}$ & 0.064 \\
\hline $\mathrm{Co}+\mathrm{Yb}+\mathrm{Cr}$ & C $6.82^{\mathrm{a}}$ & 0.106 & $\mathrm{C} 9.48^{\mathrm{a}}$ & 0.029 & B $5 \cdot 80^{\mathrm{C}}$ & 0.109 & B $8 \cdot 17^{\mathrm{a}}$ & 0.106 \\
\hline $\mathrm{Co}+\mathrm{Yb}+\mathrm{INDF}$ & $\mathrm{C} 6.88^{\mathrm{a}}$ & 0.073 & C $9.54^{\mathrm{a}}$ & 0.087 & B $6.07^{b}$ & 0.119 & $\mathrm{~B} 8 \cdot 16^{\mathrm{a}}$ & 0.116 \\
\hline
\end{tabular}

INDF, indigestible neutral-detergent fibre.

$A, B, C$ Within a column, marker systems analysed using a common statistical model are denoted by common prefixes.

$a, b, c, d$ Mean values within a column (with a common prefix) with unlike superscript letters were significantly different $(P<0.05)$.

${ }^{*}$ For details of procedures, see pp. 42-43. 
Table 8. Correlation coefficients between estimates of organic-matter flow entering the omasal canal derived using different marker systems $†$

(Mean values of four studies)

\begin{tabular}{|c|c|c|c|c|c|c|c|c|}
\hline & $\mathrm{Yb}$ & $\mathrm{Cr}$ & INDF & $\mathrm{Co}+\mathrm{Yb}$ & $\mathrm{Co}+\mathrm{Cr}$ & Co + INDF & $\mathrm{Co}+\mathrm{Yb}+\mathrm{Cr}$ & $\mathrm{Co}+\mathrm{Yb}+$ INDF \\
\hline Co & 0.62 & 0.35 & 0.22 & 0.52 & $0.75^{\star}$ & $0.70^{*}$ & 0.52 & 0.48 \\
\hline $\mathrm{Yb}$ & & $0 \cdot 70^{*}$ & $0.62^{*}$ & $0.98^{*}$ & $0.80^{\star}$ & $0.77^{*}$ & $0.94^{\star}$ & $0.93^{*}$ \\
\hline $\mathrm{Cr}$ & & & $0.92^{*}$ & $0.72^{*}$ & $0.84^{\star}$ & $0.79^{*}$ & $0.88^{\star}$ & $0.85^{\star}$ \\
\hline INDF & & & & $0.64^{*}$ & $0.72^{*}$ & $0.77^{\star}$ & $0.78^{\star}$ & $0.81^{*}$ \\
\hline $\mathrm{Co}+\mathrm{Yb}$ & & & & & $0.75^{\star}$ & $0.72^{*}$ & $0.95^{\star}$ & $0.95^{\star}$ \\
\hline $\mathrm{Co}+\mathrm{Cr}$ & & & & & & $0.96^{\star}$ & $0.87^{*}$ & $0.84^{*}$ \\
\hline Co + INDF & & & & & & & $0.83^{\star}$ & $0.85^{\star}$ \\
\hline $\mathrm{Co}+\mathrm{Yb}+\mathrm{Cr}$ & & & & & & & & $0.99^{*}$ \\
\hline
\end{tabular}

INDF, indigestible neutral-detergent fibre.

* Correlation coefficients were significantly $(P<0.05)$ different from zero for at least three of the four studies.

$\dagger$ For details of procedures, see pp. 42-43.

systems (Table 9). Furthermore, estimates of $\mathrm{N}$ flow based on $\mathrm{Co}+\mathrm{Yb}$ were in good agreement with those derived using triple-marker systems. Relative to $\mathrm{Co}+\mathrm{Yb}$ and all triple-marker systems, $\mathrm{N}$ flow estimated using $\mathrm{Co}+\mathrm{Cr}$ and Co + INDF was highly variable, such that differences were significant in experiments II, III and IV. CV associated with estimates of $\mathrm{N}$ flow using different marker systems were relatively consistent, except for experiment IV where variance in $\mathrm{N}$ flow based on $\mathrm{Co}+\mathrm{Cr}$ and $\mathrm{Co}+$ INDF was much lower compared with other marker systems.

Estimates of $\mathrm{N}$ flow based on Co were poorly correlated with those derived using alternative single markers (Table 10). Comparison of single-marker systems indicated that the strongest relationship existed between $\mathrm{N}$ flows estimated according to $\mathrm{Cr}$ and INDF solid-phase markers. Further examination of the correlation coefficients between estimates calculated according to single- and triple-marker systems indicated that use of $\mathrm{Yb}$ resulted in estimates that were most strongly related with those derived using triplemarker systems.

Neutral-detergent fibre. Estimates of NDF flow entering the omasal canal were, with the exception of experiment III, similar for both two triple-marker systems (Table 11). For double-marker systems, estimates based on $\mathrm{Co}+\mathrm{Cr}$ and $\mathrm{Co}+\mathrm{INDF}$ were in general consistent, with the exception of experiment III, where differences were larger and statistically significant. In general, use of
$\mathrm{Co}+\mathrm{Yb}$ resulted in lower NDF flows compared with alternative double-marker systems. Within studies, associated $\mathrm{CV}$ of NDF flows was markedly different between marker systems, the extent of which was inconsistent between studies.

Estimates of NDF flow based on Co were more closely correlated with those derived using $\mathrm{Yb}$ compared with $\mathrm{Cr}$ or INDF (Table 12). Furthermore, correlation coefficients between flows estimated using single- and corresponding double-marker systems indicated that closer relationships existed between particulate markers ( $\mathrm{Yb}, \mathrm{Cr}$ and INDF) than with Co. Similarly, correlation coefficients between estimates based on single- and triple-marker systems were higher for $\mathrm{Cr}$ and INDF than those derived using $\mathrm{Co}$ or $\mathrm{Yb}$.

Ruminal NDF digestibility as a proportion of total tract NDF digestibility was similar for the triple-marker systems, with the exception of experiment III, where digestibility in the rumen based on $\mathrm{Co}+\mathrm{Yb}+\mathrm{Cr}$ exceeded total tract NDF digestibility (Table 13). Values based on double-marker systems were consistent between $\mathrm{Co}+$ $\mathrm{Cr}$ and $\mathrm{Co}+\mathrm{INDF}$ in experiments I and II, whereas measurements from experiments III and IV indicated significant differences between these systems. With the exception of experiment $\mathrm{II}$, use of $\mathrm{Co}+\mathrm{Yb}$ indicated that a higher proportion of total NDF digestion occurred in the rumen than for $\mathrm{Co}+\mathrm{Cr}$ or $\mathrm{Co}+\mathrm{INDF}$ doublemarker systems.

Table 9. Effect of marker system on estimates of nitrogen flow $(\mathrm{g} / \mathrm{d})$ entering the omasal canal ${ }^{*}$ (Mean values and coefficient of variation)

\begin{tabular}{|c|c|c|c|c|c|c|c|c|}
\hline \multirow{2}{*}{$\begin{array}{l}\text { Expt... } \\
\text { Marker }\end{array}$} & \multicolumn{2}{|c|}{1} & \multicolumn{2}{|c|}{ II } & \multicolumn{2}{|c|}{ III } & \multicolumn{2}{|c|}{ IV } \\
\hline & Mean & $\mathrm{CV}$ & Mean & $\mathrm{CV}$ & Mean & $\mathrm{CV}$ & Mean & $\mathrm{CV}$ \\
\hline $\mathrm{Co}+\mathrm{Yb}$ & A $312^{a}$ & 0.053 & A $480^{\circ}$ & 0.056 & A $341^{b}$ & 0.087 & A $489^{a}$ & 0.124 \\
\hline $\mathrm{Co}+\mathrm{Cr}$ & A $310^{a}$ & 0.087 & A $440^{\mathrm{b}}$ & 0.038 & A $433^{a}$ & 0.061 & A $411^{\mathrm{b}}$ & 0.033 \\
\hline Co + INDF & A $311^{a}$ & 0.058 & A $439^{b}$ & 0.049 & A $360^{b}$ & 0.078 & A $406^{\mathrm{C}}$ & 0.035 \\
\hline $\mathrm{Co}+\mathrm{Yb}+\mathrm{Cr}$ & B $321^{a}$ & 0.058 & B $479^{a}$ & 0.044 & B $348^{a}$ & 0.092 & A $491^{a}$ & 0.118 \\
\hline $\mathrm{Co}+\mathrm{Yb}+$ INDF & B $321^{a}$ & 0.054 & B $479^{a}$ & 0.046 & B $350^{\mathrm{a}}$ & 0.090 & A $491^{\mathrm{a}}$ & 0.118 \\
\hline
\end{tabular}

INDF, indigestible neutral-detergent fibre.

A,B Within a column, marker systems analysed using a common statistical model are denoted by common prefixes.

$a, b, c$ Mean values within a column, (with a common prefix) with unlike superscript letters were significantly different $(P<0.05)$.

${ }^{*}$ For details of procedures, see pp. $42-43$ 
Table 10. Correlation coefficients between estimates of nitrogen flow entering the omasal canal derived using different marker systems $\dagger$

(Mean values of four studies)

\begin{tabular}{|c|c|c|c|c|c|c|c|c|}
\hline & $\mathrm{Yb}$ & $\mathrm{Cr}$ & INDF & $\mathrm{Co}+\mathrm{Yb}$ & $\mathrm{Co}+\mathrm{Cr}$ & Co + INDF & $\mathrm{Co}+\mathrm{Yb}+\mathrm{Cr}$ & $\mathrm{Co}+\mathrm{Yb}+\mathrm{INDF}$ \\
\hline Co & $0.54^{*}$ & 0.38 & 0.32 & $0.57^{\star}$ & $0.88^{*}$ & $0.88^{*}$ & $0.59^{*}$ & $0.59^{*}$ \\
\hline $\mathrm{Yb}$ & & $0.79^{*}$ & $0.73^{*}$ & $0.99^{\star}$ & $0.75^{\star}$ & $0.71^{*}$ & $0.99^{*}$ & $0.99^{*}$ \\
\hline $\mathrm{Cr}$ & & & $0.94^{*}$ & $0.78^{*}$ & $0.72^{*}$ & $0.66^{*}$ & $0.79^{*}$ & $0.79^{*}$ \\
\hline INDF & & & & $0.71^{*}$ & $0.65^{\star}$ & $0.63^{*}$ & $0.73^{*}$ & $0.73^{*}$ \\
\hline $\mathrm{Co}+\mathrm{Yb}$ & & & & & $0.77^{*}$ & $0.72^{*}$ & $1.00^{*}$ & $0.99^{*}$ \\
\hline $\mathrm{Co}+\mathrm{Cr}$ & & & & & & $0.97^{\star}$ & $0.79^{*}$ & $0.79^{*}$ \\
\hline Co + INDF & & & & & & & $0.75^{\star}$ & $0.75^{*}$ \\
\hline $\mathrm{Co}+\mathrm{Yb}+\mathrm{Cr}$ & & & & & & & & $1.00^{*}$ \\
\hline
\end{tabular}

INDF, indigestible neutral-detergent fibre.

${ }^{\star}$ Correlation coefficients were significantly $(P<0.05)$ different from zero for at least three of the four studies.

†For details of procedures, see pp. 42-43.

Table 11. Effect of marker system on estimates of neutral-detergent fibre flow $(\mathrm{kg} / \mathrm{d})$ entering the omasal canal $^{*}$

(Mean values and coefficients of variation)

\begin{tabular}{|c|c|c|c|c|c|c|c|c|}
\hline \multirow{2}{*}{$\begin{array}{l}\text { Expt... } \\
\text { Marker }\end{array}$} & \multicolumn{2}{|c|}{ I } & \multicolumn{2}{|c|}{ II } & \multicolumn{2}{|c|}{ III } & \multicolumn{2}{|c|}{ IV } \\
\hline & Mean & CV & Mean & CV & Mean & CV & Mean & CV \\
\hline $\mathrm{Co}+\mathrm{Yb}$ & A 2.18 & 0.146 & A $4.58^{a}$ & 0.051 & A $1.24^{C}$ & 0.154 & A $2 \cdot 30^{d}$ & 0.153 \\
\hline $\mathrm{Co}+\mathrm{Cr}$ & B 3.10 & 0.130 & A $4.73^{a}$ & 0.047 & A $2 \cdot 11^{\mathrm{b}}$ & 0.071 & A $2 \cdot 83^{a}$ & 0.080 \\
\hline Co + INDF & C 3.13 & 0.081 & A $4.70^{\mathrm{a}}$ & 0.092 & A $2.43^{\mathrm{a}}$ & 0.079 & A $2.73^{\mathrm{C}}$ & 0.092 \\
\hline $\mathrm{Co}+\mathrm{Yb}+\mathrm{Cr}$ & D $3.07^{a}$ & 0.127 & B $4.64^{\mathrm{a}}$ & 0.091 & B $2 \cdot 11^{\mathrm{b}}$ & 0.084 & A $2.76^{\text {bc }}$ & 0.074 \\
\hline $\mathrm{Co}+\mathrm{Yb}+\mathrm{INDF}$ & D $3 \cdot 14^{\mathrm{a}}$ & 0.078 & B $4.71^{\mathrm{a}}$ & 0.141 & B $2.38^{\mathrm{a}}$ & 0.083 & A $2 \cdot 75^{\mathrm{b}}$ & 0.095 \\
\hline
\end{tabular}

INDF, indigestible neutral-detergent fibre.

A,B,C,D Within a column, marker systems analysed using a common statistical model are denoted by common prefixes.

${ }^{a, b, c, d}$ Mean values within a column, (with a common prefix) with unlike superscript letters were significantly different $(P<0.05)$.

${ }^{*}$ For details of procedures, see pp. 42-43.

Table 12. Correlation coefficients between estimates of neutral-detergent fibre flow entering the omasal canal derived using different marker systems $†$

(Mean values of four studies)

\begin{tabular}{|c|c|c|c|c|c|c|c|c|}
\hline & $\mathrm{Yb}$ & $\mathrm{Cr}$ & INDF & $\mathrm{Co}+\mathrm{Yb}$ & $\mathrm{Co}+\mathrm{Cr}$ & Co + INDF & $\mathrm{Co}+\mathrm{Yb}+\mathrm{Cr}$ & $\mathrm{Co}+\mathrm{Yb}+\mathrm{INDF}$ \\
\hline Co & $0.79^{*}$ & $0.62^{*}$ & 0.36 & $0.66^{\star}$ & 0.50 & 0.43 & 0.53 & 0.42 \\
\hline $\mathrm{Yb}$ & & $0.77^{*}$ & $0.61^{*}$ & $0.97^{*}$ & $0.70^{*}$ & $0.66^{*}$ & $0.67^{*}$ & $0.67^{\star}$ \\
\hline $\mathrm{Cr}$ & & & $0.85^{*}$ & $0.75^{*}$ & $0.98^{*}$ & $0.90^{*}$ & $0.98^{*}$ & $0.90^{*}$ \\
\hline INDF & & & & $0.62^{*}$ & $0.86^{*}$ & $0.98^{*}$ & $0.85^{\star}$ & $0.98^{*}$ \\
\hline $\mathrm{Co}+\mathrm{Yb}$ & & & & & $0.70^{*}$ & $0.67^{\star}$ & $0.65^{\star}$ & $0.68^{*}$ \\
\hline $\mathrm{Co}+\mathrm{Cr}$ & & & & & & $0.91^{*}$ & $0.99^{*}$ & $0.91^{*}$ \\
\hline $\mathrm{Co}+\mathrm{INDF}$ & & & & & & & $0.90^{*}$ & $1.00^{*}$ \\
\hline $\mathrm{Co}+\mathrm{Yb}+\mathrm{Cr}$ & & & & & & & & $0.90^{\star}$ \\
\hline
\end{tabular}

INDF, indigestible neutral-detergent fibre.

${ }^{*}$ Correlation coefficients were significantly $(P<0.05)$ different from zero for at least three of the four studies.

†For details of procedures, see pp. 42-43.

\section{Reconstitution factors}

With one exception (experiment II), RF for liquid and small-particle phases calculated according to triplemarker systems were negative (Table 14). Negative RF suggest that relative to large particulate matter, digesta collected from the omasal canal contained excessive amounts of liquid and small particulate matter.

\section{Sensitivity study}

Simulation of proportionate $0 \cdot 10$ overestimates of daily Co administration had only minor effects on OM, N and NDF flow (Table 15). Similarly, simulations of excessive $\mathrm{Yb}$ administration had only minor effects on NDF flow, but resulted in respective proportionate 0.06 and 0.09 increases in $\mathrm{OM}$ and $\mathrm{N}$ flow. In contrast, overestimation of daily $\mathrm{Cr}$ 
Table 13. Effect of marker system on the proportion of total tract neutral-detergent fibre digestion occurring in the rumen†

(Mean values and standard deviations)

\begin{tabular}{|c|c|c|c|c|c|c|c|c|}
\hline \multirow{2}{*}{$\begin{array}{l}\text { Expt... } \\
\text { Marker }\end{array}$} & \multicolumn{2}{|c|}{ I } & \multicolumn{2}{|c|}{ II } & \multicolumn{2}{|c|}{ III } & \multicolumn{2}{|c|}{ IV } \\
\hline & Mean & SD & Mean & SD & Mean & SD & Mean & SD \\
\hline $\mathrm{Co}+\mathrm{Yb}$ & A $1.135^{a *}$ & 0.086 & A $0.913^{a *}$ & 0.093 & A $1.234^{a *}$ & 0.033 & A $1.043^{a *}$ & 0.062 \\
\hline $\mathrm{Co}+\mathrm{Cr}$ & A $0.906^{b *}$ & 0.087 & A $0.881^{a *}$ & 0.047 & A $1.053^{b *}$ & 0.027 & A $0.943^{C *}$ & 0.021 \\
\hline Co + INDF & A $0.896^{b *}$ & 0.038 & A $0.892^{a *}$ & 0.044 & A $0.987^{d}$ & 0.029 & A $0.963^{b *}$ & 0.018 \\
\hline $\mathrm{Co}+\mathrm{Yb}+\mathrm{Cr}$ & B $0.912^{a *}$ & 0.092 & B $0.899^{a *}$ & 0.051 & A $1.053^{b *}$ & 0.025 & B $0.958^{a *}$ & 0.026 \\
\hline $\mathrm{Co}+\mathrm{Yb}+$ INDF & B $0.895^{a *}$ & 0.031 & B $0.888^{a *}$ & 0.043 & A $0.996^{C}$ & 0.023 & B $0.960^{a *}$ & 0.021 \\
\hline
\end{tabular}

INDF, indigestible neutral-detergent fibre.

A,B Within a column, marker systems analysed using a common statistical model are denoted by common prefixes.

a,b,c,d Mean values within a column (with a common prefix) with unlike superscript letters were significantly different $(P<0.05)$

${ }^{*}$ Mean values were significantly $(P<0.05)$ different from 1.00

†For details of procedures, see pp. $42-43$.

Table 14. Reconstitution factors ${ }^{*}$ for liquid and small-particle phases $†$ (Mean values and standard deviations)

\begin{tabular}{|c|c|c|c|c|c|c|c|c|}
\hline \multirow{2}{*}{$\begin{array}{l}\text { Expt... } \\
\text { Digesta phase }\end{array}$} & \multicolumn{2}{|c|}{ I } & \multicolumn{2}{|c|}{ II } & \multicolumn{2}{|c|}{ III } & \multicolumn{2}{|c|}{ IV } \\
\hline & Mean & SD & Mean & SD & Mean & SD & Mean & SD \\
\hline \multicolumn{9}{|l|}{$\mathrm{Co}+\mathrm{Yb}+\mathrm{Cr}$} \\
\hline Liquid & -0.208 & 0.095 & -0.118 & 0.068 & -0.221 & 0.063 & -0.242 & 0.066 \\
\hline Small particle & -0.116 & 0.067 & 0.000 & 0.055 & -0.212 & 0.049 & -0.086 & 0.062 \\
\hline \multicolumn{9}{|l|}{$\mathrm{Co}+\mathrm{Yb}+\mathrm{INDF}$} \\
\hline $\begin{array}{l}\text { Liquid } \\
\text { Small-particle }\end{array}$ & $\begin{array}{l}-0.210 \\
-0.123\end{array}$ & $\begin{array}{l}0.096 \\
0.059\end{array}$ & $\begin{array}{l}-0.129 \\
-0.020\end{array}$ & $\begin{array}{l}0.078 \\
0.066\end{array}$ & $\begin{array}{l}-0.251 \\
-0.241\end{array}$ & $\begin{array}{l}0.065 \\
0.050\end{array}$ & $\begin{array}{l}-0.242 \\
-0.084\end{array}$ & $\begin{array}{l}0.068 \\
0.058\end{array}$ \\
\hline
\end{tabular}

INDF, indigestible neutral-detergent fibre.

* Reconstitution factor refers to the number of units of digesta that must be added to or removed from one unit of collected digesta in order to reconstitute true digesta.

†For details of procedures, see pp. 42-43.

or INDF doses had little effect on $\mathrm{N}$ flow, but resulted in proportionate increases in the flow of NDF $(0 \cdot 11$ and 0.10 respectively) and $\mathrm{OM}(0.04)$ entering the omasal canal.

\section{Discussion}

Due to the inability to validate estimates of digesta flow with true reference measurements, the merits and demerits of marker methods have to be evaluated on the basis of the theoretical considerations. Determination of digesta DM flow using indigestible markers is based on marker concentrations in digesta relative to the amount administered. Use of the reconstitution technique (Faichney, 1975) is based on the assumption that the flow of digesta is similar for any given marker provided that the sample collected is truly representative of digesta flowing past the sampling site. Unless a marker is uniformly distributed across all digesta phases, unrepresentative sampling alters the concentration in the sample relative to that in true digesta, which is reflected as differences in estimates of digesta flow between markers. The present evaluation indicated substantial between-marker differences in estimates of OM flow entering the omasal canal. Since markers exhibited substantial variation in the distribution between digesta
Table 15. Relative change in organic-matter (OM), nitrogen and neutral-detergent fibre (NDF) flow estimated using triple-marker systems in a response to a proportionate 0.10 overestimation of marker administration*

Relative response in flow entering the omasa canal

\begin{tabular}{lccc}
\hline Overestimated marker & OM & $\mathrm{N}$ & NDF \\
\hline Co $+\mathrm{Yb}+\mathrm{Cr}$ & & & \\
Co & 1.00 & 1.01 & 1.00 \\
$\mathrm{Yb}$ & 1.06 & 1.09 & 0.99 \\
$\mathrm{Cr}$ & 1.04 & 1.01 & 1.11 \\
$\mathrm{Co}+\mathrm{Yb}+\mathrm{INDF}$ & & & \\
$\mathrm{Co}$ & 1.00 & 1.01 & 1.00 \\
Yb & 1.07 & 1.09 & 1.00 \\
INDF & 1.04 & 1.00 & 1.10 \\
\hline
\end{tabular}

INDF, indigestible neutral-detergent fibre.

${ }^{*}$ For details of procedures, see pp. 42-43.

phases, this finding can be interpreted as an indication of the extent of unrepresentative sampling. However, differences between markers may also arise from diurnal variations in digesta marker concentrations (Owens \& Hanson, 1992; Gill et al. 1999) and errors associated 
with the determination of marker concentrations. These sources of variation can be minimised by frequent sampling (Gill et al. 1999) and ensuring analytical methods used to measure marker concentrations are reliable.

\section{Reconstitution of true digesta}

Unrepresentative samples can be reconstituted to represent true digesta provided that the markers used are intimately associated with individual digesta phases that exhibit unique flow characteristics. Markers do not necessarily have to be uniquely associated with a single phase but should be preferentially concentrated with one phase relative to all the others (France \& Siddons, 1986). Furthermore, the reconstitution method assumes that digesta phases are entirely homogeneous such that the composition of each phase in unrepresentative samples is similar to that in true digesta (Faichney, 1993). Liquid and small-particle phases appear to satisfy this criterion. In contrast, large particulate matter consists of particles that vary both in size and physical and chemical characteristics (Ahvenjärvi et al. 2001). Because fractionation of large particles into several sub-fractions is impractical, markers of this phase should be uniformly distributed across particle sizes.

Use of the double-marker system is based on the assumption that digesta consists of two distinct phases. In order to reconstitute, unrepresentative digesta has to be divided into separate phases that are selectively enriched with a given marker. In the case that small particles associate with the fluid fraction, digesta should be separated by filtration rather than centrifugation (Faichney, 1993). Since Yb was concentrated in small particulate matter, the distribution of $\mathrm{Yb}$ between solid and fluid phases was dependent on the method used to separate digesta (Table 5). Separation by filtration resulted in a similar distribution of $\mathrm{Co}$ and $\mathrm{Yb}$ concentrations between phases, such that the doublemarker system becomes more susceptible to analytical error. If small particles exhibit flow characteristics that are dissimilar to that of liquid or large particulate matter, then the weak association with these phases renders $\mathrm{Yb}$ unsuitable as a reliable solid-phase marker.

The effect of unrepresentative sampling on the concentration of a marker relative to an individual chemical entity is dependent on the association between these two parameters. In the case that a marker is intimately associated with a specific chemical component, unrepresentative sampling will influence marker concentrations in sample $\mathrm{DM}$, but has no effect on the ratio of the marker relative to the component of interest. Consequently, when the flow of digesta is estimated using a single-marker system, unrepresentative sampling affects the flow of DM, but has no effect on the chemical entity with which it is intimately associated.

Calculation of RF (Table 14) based on triple-marker systems demonstrated the unrepresentative nature of digesta collected from the omasal canal. Since reconstitution substantially altered the relative proportions of digesta phases, comparison of flows estimated according to single- and triple-marker systems can be considered to reflect the extent of association between markers and chemical components.

\section{Markers}

None of the markers was uniformly distributed across all digesta phases. Co was primarily associated with the liquid phase, $\mathrm{Yb}$ with small particles, and $\mathrm{Cr}$-mordanted straw and INDF with large particulate matter (Table 3).

Cobalt. The EDTA complex of $\mathrm{Co}$ and $\mathrm{Cr}$ are often used as liquid-phase markers. Because DM in the liquid phase is almost exclusively comprised of inorganic matter and volatile fatty acids (Table 2), the association between $\mathrm{Co}$ and measured chemical components was the weakest of all the markers evaluated. This lack of association was reflected by only modest correlations between estimates of OM, N and NDF flow based on Co compared with those derived using alternative single- or triplemarker systems. Furthermore, estimates of the flow of these nutrients were largely independent of Co administration. It would be expected that double-marker systems based on $\mathrm{Yb}+\mathrm{Cr}$ or $\mathrm{Yb}+\mathrm{INDF}$ would provide more accurate estimates of the flow of insoluble components than that based on $\mathrm{Co}$ and a particle-phase marker. This suggestion is supported by close correlations between estimates of $\mathrm{OM}$ flow based on $\mathrm{Yb}+\mathrm{Cr}$ and $\mathrm{Co}+\mathrm{Yb}+\mathrm{Cr}$ $(r$ 0.99) and between OM flows derived using $\mathrm{Yb}+\mathrm{INDF}$ compared with $\mathrm{Co}+\mathrm{Yb}+\mathrm{INDF}$ ( $r$ 0.99; data not presented). It appears that $\mathrm{Co}$ is not the marker of choice for the determination of organic components, but this may not be the case for studies that attempt to measure the supply of water-soluble nutrients.

Ytterbium. Yb has been used extensively as a solidphase marker within double-marker systems (for example, Ortigues et al. 1990; Huhtanen et al. 1997) following the observation that proportionately 0.93 of administered $\mathrm{Yb}$ is associated with particulate matter in duodenal digesta (Siddons et al. 1985). Use of alternative procedures that provide a more rigorous labelling of $\mathrm{Yb}$ with fibre fractions (Ellis et al. 2002) could be expected to improve the association with particulate matter. However, when $\mathrm{Yb}$ is infused in the rumen this marker exhibits a greater affinity for small- compared with medium- or large-sized particles (Siddons et al. 1985; Combs et al. 1992) and explains the separation-dependent effects on $\mathrm{Yb}$ distribution in omasal digesta (Table 5). Consequently, the method used to separate digesta also affected the estimates of OM and $\mathrm{NDF}$ flow derived using the $\mathrm{Yb}+\mathrm{Co}$ double-marker system (Table 6). On the basis of theoretical considerations and variance associated with measurements of $\mathrm{OM}$ and NDF flow, separating digesta by centrifugation appears to be more reliable than filtration.

A close relationship between estimates of $\mathrm{N}$ flow based on $\mathrm{Yb}$ and triple-marker systems $\left(\begin{array}{rr}r & 0.99\end{array}\right)$ indicates that concentrations of $\mathrm{Yb}$ relative to $\mathrm{N}$ are much the same in unrepresentative and reconstituted digesta. Examination of the sensitivity of flows to marker administration (Table 15) suggests that the accuracy of $\mathrm{N}$ flows estimated using triple-marker systems is largely governed by $\mathrm{Yb}$ concentrations. Furthermore, concentrations of $\mathrm{Yb}$ and $\mathrm{N}$ were lowest in the liquid phase and highest in small particulate matter (Tables 2 and 3). Such findings provide tentative evidence of an intimate association between $\mathrm{Yb}$ and nitrogenous compounds. 
It appears that the weaker relationships between $\mathrm{N}$ flows estimated using $\mathrm{Co}, \mathrm{Cr}$, and INDF compared with triplemarker systems are related to the lower affinity of these markers with $\mathrm{N}$ fractions in digesta relative to that of $\mathrm{Yb}$. In contrast, $\mathrm{Yb}$ was not as closely associated with fibrous material as $\mathrm{Cr}$ or INDF; that could arise from small particles existing as a suspension and therefore having a higher affinity with the liquid phase than fibrous particulate matter. The closer relationship between NDF flows based on $\mathrm{Yb}$ with $\mathrm{Co}$ than $\mathrm{Cr}$ or INDF tends to support this suggestion. Furthermore, mean retention times of 11.2 and $12.4 \mathrm{~h}$ for CrEDTA and $\mathrm{Yb}$ acetate administered in the rumen (Faichney et al. 1997) indicate that the passage kinetics of $\mathrm{Yb}$ approach that of rumen fluid, with the implication that $\mathrm{Yb}$ should not be considered as an ideal solid-phase marker within double-marker systems. A higher digestibility of NDF in the rumen than the total tract (Table 13) when $\mathrm{Yb}$ was used as a solid-phase marker is clearly erroneous and indicates that the flow of NDF flow entering the omasal canal in such cases is underestimated. Errors in the estimation of NDF flow arise from the weak association between $\mathrm{Yb}$ and fibrous particulate matter in omasal digesta.

In spite of an intimate association between $\mathrm{Yb}$ and $\mathrm{N}$ concentrations, variance in the estimates of $\mathrm{N}$ flow based on $\mathrm{Co}+\mathrm{Cr}$ and $\mathrm{Co}+\mathrm{INDF}$ was comparable to, or lower than, that derived according to $\mathrm{Yb}$-based doublemarker systems. Use of $\mathrm{Yb}$ would be expected to provide more reliable measurements of $\mathrm{N}$ flow entering the omasal canal, indicating that associated variance is not a true measure of the relative accuracy of marker systems. Higher variance associated with estimates of $\mathrm{N}$ flow in experiment IV can be attributed to the lower precision of $\mathrm{Yb}$ determinations compared with other markers (Table 4).

Chromium and indigestible neutral-detergent fibre. Close relationships between estimates of NDF flow based on $\mathrm{Cr}$ and $\mathrm{Co}+\mathrm{Yb}+\mathrm{Cr}$ and INDF with $\mathrm{Co}+\mathrm{Yb}+$ INDF indicate that concentrations of $\mathrm{Cr}$ and INDF relative to NDF were similar for unrepresentative and reconstituted digesta. Because $\mathrm{Cr}$, INDF and NDF are primarily associated with large particulate matter, changes in the relative proportions of digesta phases had only minor effects on the concentration of $\mathrm{Cr}$ or INDF with respect to NDF. Small differences between NDF flows based on Cr and INDF can be attributed to the inherent precision of marker determinations and the variation in the distribution of $\mathrm{Cr}$ and INDF of large particulate matter. The distribution of $\mathrm{Cr}$ and INDF is known to be dependent on particle size, such that concentrations of $\mathrm{Cr}$ decrease and that of INDF increase with concomitant reductions in particle size (Ahvenjärvi et al. 2001). The unique distribution between various particle size fractions suggests that the use of both $\mathrm{Cr}$ and INDF would further improve the accuracy of NDF flows compared with either marker alone (Ahvenjärvi et al. 2001).

Flows based on $\mathrm{Cr}$ and INDF-based double- and triplemarker systems were in most cases in good agreement and provided biologically realistic estimates of the proportion of total NDF digestion occurring in the rumen (Table 13). In contrast, use of Co in combination with $\mathrm{Yb}$ resulted in values of NDF digestion in the rumen that exceeded that in the total tract.

\section{Marker administration}

Marker administration is subject to variation owing to inconsistencies in infusion rate or occasional leakage from cannulas. When complexed with EDTA, relatively minor amounts of $\mathrm{Cr}$ can be absorbed from the gastrointestinal tract and subsequently excreted in urine (Faichney, 1975; Siddons et al. 1985). Inaccuracies in the determination of marker concentrations can also contribute to erroneous between-marker differences in digesta flow. Determination of markers using atomic absorption spectrometry or plasma emission spectroscopy is susceptible to error (Siddons et al. 1985; Combs \& Satter, 1992). $\mathrm{Cr}$ absorption is lowered proportionately by between $0 \cdot 10$ and 0.20 due to interfering compounds in faeces (Holt, 1993), which may explain incomplete faecal recoveries of $\mathrm{Cr}$ reported in the literature (for example, Titgemeyer, 1997). The influence of interfering compounds can be minimised when markers are analysed in combination with a suitable background matrix such as reference samples of digesta or faeces (Siddons et al. 1985; Combs \& Satter, 1992). In order to account for these effects, daily rates of marker administration were determined on the basis of marker excretion in faeces in the present studies.

\section{Choice of marker method}

Differences in OM flow based on single markers are consistent with previous findings reported for $\mathrm{Co}, \mathrm{Yb}$ and $\mathrm{Cr}$ (Huhtanen et al. 1997) and indicate that samples collected from the omasal canal are not truly representative of digesta entering the sampling site. Compared with sampling of digesta from the duodenum, deviations from true digesta tend to be larger for samples collected from the omasal canal (Ahvenjärvi et al. 2000). Calculation of RF using triple-marker systems indicated that omasal canal digesta was comprised of at least three distinct phases that tended to separate during sampling. OM in digesta is concentrated in particulate matter, such that the use of Co to assess the flow of organic components is unreliable due the low affinity for small and large particles. Further examination of marker distribution in digesta indicates that $\mathrm{Yb}$ is intimately associated with nitrogenous components, whilst $\mathrm{Cr}$ and INDF were concentrated in fibre-rich fractions. Double-marker systems based on $\mathrm{Yb}$ in combination with $\mathrm{Cr}$ or INDF should be sufficiently reliable for the determination of $\mathrm{OM}, \mathrm{N}$ and NDF flow. Concentrations of particulate markers were relatively low in the liquid phase, such that the use of Co within a triple-marker system would be expected to improve further the accuracy of estimates of total digesta flow.

\section{References}

AFRC (1990) Nutritive requirements of ruminant animals: energy. Nutr Abstr Rev 60B, 729-804.

AFRC (1992) Nutritive requirements of ruminant animals: energy. Nutr Abstr Rev 62B, 787-835.

Ahvenjärvi S, Joki-Tokola E, Vanhatalo A, Jaakkola S \& Huhtanen P (2002a) Effects of gradual replacement of grass 
silage with whole-crop barley silage on ruminal metabolism, digestibility and milk production in dairy cows. In The XIIIth International Silage Conference, pp. 320-321 [LM Gechie and $\mathrm{C}$ Thomas, editors]. Auchincruive, UK: SAC.

Ahvenjärvi S, Skiba B \& Huhtanen P (2001) Effect of heterogeneous digesta chemical composition on the accuracy of measurements of fiber flow in dairy cows. J Anim Sci 79, $1611-1620$.

Ahvenjärvi S, Vanhatalo A \& Huhtanen P (2002b) Supplementing barley or rapeseed meal to dairy cows fed grass-red clover silage: 1. Rumen degradability and microbial flow. J Anim Sci 80, 2176-2187.

Ahvenjärvi S, Vanhatalo A, Huhtanen P \& Varvikko T (1999) Effects of supplementation of a grass silage and barley diet with urea, rapeseed meal and heat-moisture-treated rapeseed cake on omasal digesta flow and milk production in lactating dairy cows. Acta Agric Scand 49A, 179-189.

Ahvenjärvi S, Vanhatalo A, Huhtanen P \& Varvikko T (2000) Determination of reticulo-rumen and whole-stomach digestion in lactating cows by omasal canal or duodenal sampling. Br J Nutr 83, 67-77.

Combs DK \& Satter LD (1992) Determination of markers in digesta and feces by direct current plasma emission spectroscopy. J Dairy Sci 75, 2176-2182.

Combs DK, Shaver RD \& Satter LD (1992) Retention of rare earths by hay particles following incubation in fresh or autoclaved rumen fluid. $J$ Dairy Sci 75, 132-139.

Ellis WC, Wylie MJ \& Matis JH (2002) Validity of specifically applied rare earth elements and compartmental models for estimating flux of undigested plant tissue residues through the gastrointestinal tract of ruminants. J Anim Sci 80, 2753-2758.

Faichney GJ (1975) The use of markers to partition digestion within the gastrointestinal tract of ruminants. In Digestion and Metabolism in the Ruminant. Proceedings of the IVth International Symposium on Ruminant Physiology, pp. 277-291 [IW McDonald and ACI Warner, editors]. Sydney, Australia: The University of New England Publishing Unit.

Faichney GJ (1993) Digesta flow. In Quantitative Aspects of Ruminant Digestion and Metabolism, pp. 53-85 [JM Forbes and J France, editors]. Wallingford, UK: CAB International.

Faichney GJ, Poncet C, Lassalas B, et al. (1997) Effect of concentrates in a hay diet on the contribution of anaerobic fungi, protozoa and bacteria to nitrogen in rumen and duodenal digesta in sheep. Anim Feed Sci Technol 64, 193-213.

France J \& Siddons RC (1986) Determination of digesta flow by continuous marker infusion. $J$ Theor Biol 121, 105-119.

Gill M, Robinson PH \& Kennelly JJ (1999) Diurnal patterns in rumen volume and composition of digesta flowing into the duodenum. Anim Sci 69, 237-249.
Holt NW (1993) Calibration curves for the determination of low levels of chromium in feces. Can J Anim Sci 73, 109-115.

Huhtanen P, Brotz PG \& Satter LD (1997) Omasal sampling technique for assessing fermentative digestion in the forestomach of dairy cows. J Anim Sci 75, 1380-1392.

Huhtanen P, Kaustell K \& Jaakkola S (1994) The use of internal markers to predict total digestibility and duodenal flow of nutrients in cattle given six different diets. Anim Feed Sci Technol 48, 211-227.

Huida L, Väätäinen H \& Lampila M (1986) Comparison of dry matter contents in grass silages as determined by oven drying and gas chromatographic water analysis. Ann Agric Fenniae 25, 215-230.

Littell RC, Milliken GA, Stroup WW \& Wolfinger RD (1996) SAS System for Mixed Models. Cary, NC: SAS Institute Inc.

National Research Council (2001) Nutrient Requirements of Dairy Cattle, 7th revised ed., National Academic Press: Washington, DC.

Ortigues I, Oldham JD, Smith T, de Courtenay MB \& Siviter JW (1990) A comparison between ytterbium acetate, ruthenium phenanthroline and indigestible acid detergent fibre in a double-marker system for intestinal flow measurements in steers. J Agric Sci 114, 69-77.

Owens FN \& Hanson CF (1992) External and internal markers for appraising site and extent of digestion in ruminants. J Dairy Sci 75, 2605-2617.

Satter LD, Lopez-Guisa JM \& Combs DK (1987) Utilization of maize crop residues by growing dairy heifers and use of rare earth elements as digesta markers in the gut. In Isotope Aided Studies on Non-protein Nitrogen and Agro-industrial By-products Utilization by Ruminants, pp. 89-101. Vienna, Austria: International Atomic Energy Agency.

Siddons RC, Paradine J, Beever DE \& Cornell PR (1985) Ytterbium acetate as a particulate-phase digesta-flow marker. Br J Nutr 54, 509-519.

St-Pierre NR (2001) Invited review: Integrating quantitative findings from multiple studies using mixed model methodology. J Dairy Sci 84, 741-755.

Titgemeyer EC (1997) Design and interpretation of nutrient digestion studies. J Anim Sci 75, 2235-2247.

Udén P, Colucci PE \& Van Soest PJ (1980) Investigation of chromium, cerium and cobalt as markers in digesta. Rate of passage studies. J Sci Food Agric 31, 625-632.

Van Soest PJ, Robertson JB \& Lewis BA (1991) Methods for dietary fiber, neutral detergent fiber and nonstarch polysaccharides in relation to animal nutrition. J Dairy Sci 74, 3583-3597.

Williams CH, David D \& Riismaa O (1962) The determination of chromic oxide in faeces samples by atomic absorption spectrometry. J Agric Sci 59, 381-385. 